\title{
Anthropological Perspectives in Bioethics
}

Kearsley A Stewart, Duke Global Health Institute, Duke University, Durham, NC, USA

(c) 2017 Elsevier Inc. All rights reserved.

\section{Introduction}

The intersection of the theories and practices of public health, anthropology, and bioethics is a recent trend. It reflects new public health challenges posed by the globalization of health research, the global spread of health technologies, epidemics of new and reemerging communicable diseases, and growing inequities in health both between countries and within countries. The field specifically identified as 'public health ethics' is still in its early stages and is broadly defined as the study of moral dilemmas in population health. Public health ethics is distinct from medical ethics; it is primarily a response by public health practitioners to such unique challenges as HIV/ AIDS research, treatment, and prevention or the complex epidemiological and public policy issues surrounding SARS and avian flu. However, there is a growing recognition in the public health world that issues typically addressed by anthropologists, ethicists, and activists, such as the relationship between culture and health behavior or the position that health is a human right, is moving to the center of the global practice of public health (Stewart et al., 2011). This suggests that public health practitioners will increasingly rely on and collaborate with anthropologists and ethicists to solve the public health challenges of the twenty-first century.

\section{Ethics}

In the public health literature, the terms ethics, morals, and values are rarely precisely defined and are, in fact, often mistakenly used interchangeably. Any discussion of ethics in public health must first clearly differentiate these distinct concepts. Values are qualities that each person wishes to embody or to guide their life; for example, honesty, compassion, generosity, tolerance, beauty, wisdom, education, wealth, etc. Morals or morality is a system of 'dos' and 'don'ts' that help guide a person's individual actions and behaviors; for example, treat others as you would have them treat you. In philosophy, ethics is a distinct field of study focusing on the principles and cultural rules that determine what is considered 'right and wrong' or 'good and evil.' For example, the study of health-related ethics is an attempt to understand why societies and biomedicine differ in their definition of a 'good death' or hold different models of 'truth-telling' between physician, patient, and family. There are two main traditions in ethics: (1) theoretical ethics which analyzes the internal logic of ethical systems and (2) normative ethics which defines and describes norms and guidelines for behaviors and action in 'real-life' situations. Public health ethics is mainly concerned with normative ethics.

\section{Bioethics}

The foundation of the philosophical application of ethical theory to health-related issues is medical ethics: an examination of the rules which define proper and good conduct between a physician and patient. However, since the 1960s, a new field of ethics, bioethics, is responding to contemporary challenges such as cases of abuse in human subjects research, entrenched physician paternalism, the rise of the patient-as-consumer and patients-rights movements, and new health technologies designed to improve or extend life, for example, in vitro fertilization or kidney dialysis. Bioethics is the study of the principles of right and wrong behaviors that guide medical research and practice with both humans and animals. It is an interdisciplinary field that focuses primarily on the moral and ethical issues that arise from the application in everyday life of biotechnological innovations in the life sciences, medicine, genetics, biology, demography, reproductive health, and the environment. Bioethics can be further subdivided into the fields of research ethics, clinical ethics, and public health ethics. Research ethics is the study of problems related to correct and appropriate conduct of lab-, clinic-, and field-based health research; clinical ethics is concerned with the challenges of patient care; and public health ethics is the study of the values and rules that guide research, action, and policy to promote population health and prevent disease.

Many universities now offer specialized programs of ethics study, some leading to advanced degrees in bioethics. Most national governments and international organizations have formal commissions to investigate the social and ethical implications of innovations in biotechnology. Bioethicists are employed by universities, hospitals, private biotechnology companies, and governments, but the practice of and resources available for bioethics varies from country to country. For example, in the United States, the growth of bioethics consultations by clinical and academic bioethicists for the private sector, especially the pharmaceutical industry, is controversial. Furthermore, there is growing concern about the dominance of English-speaking bioethicists, particularly those based in the United States, and the relatively small number of publications by scholars in the developing world. In response, a number of international initiatives, in particular the Fogarty International Center at the U.S. National Institutes of Health, offer bioethics training for scientists from resource-poor countries.

\section{Public Health Ethics}

It is helpful to distinguish public health ethics and biomedical ethics. Public health is generally concerned with improving human health and reducing disease at the population level; medicine is concerned with diagnosis and treatment of an individual patient. Public health interacts with public agencies and governments; western medicine generally focuses on the physician-patient relationship. Western medicine has a long tradition of operating within a formal code of ethics, for example, the Hippocratic Oath; in contrast, public health has only recently formalized their own code of ethics. In February 2002, the American Public Health Association became the first 
American public health organization to adopt explicitly a code of ethics, the 'Principles of the Ethical Practice of Public Health.' These principles are most noteworthy for their reaffirmation that the pursuit of public health is a moral one and the assertion that the central focus of public health ethics is to exercise power to ensure the health of populations while at the same time avoiding potential abuses related to the implementation of health interventions.

\section{Anthropology}

Anthropology is the study of the physical, biological, and cultural aspects of humankind, ranging from the evolutionary origins of Homo sapiens to the cultural significance of DNA testing and the human genome. The term anthropology is derived from Greek for anthropos (human being) and logos (word). Of all the academic disciplines that study humans, anthropology pursues the broadest approach by asking these central questions: What does it mean to be human? To what degree are humans alike or different? What is the relationship between the individual, society, biology, and culture? Is it possible to really understand how cultures other than one's own function? Two aspects of anthropology are of particular interest to the convergence of bioethics, public health practice, and public health research: the culture concept and the anthropological method.

\section{The Culture Concept}

Culture is the central organizing concept of the discipline of anthropology and it refers to everything that people create, possess, think, and do. Although this definition is so general as to be almost meaningless, most anthropologists would agree that a major feature of culture is embodied in the learned ability to transmit knowledge from one generation to the next through the spoken abstract symbols of language. In addition, the majority of contemporary anthropologists agree on three observations: (1) the development of human language and the communication of complex abstract concepts mark the emergence of human culture, (2) complex abstract language distinguishes human culture from the cultures of tool-making primates, and (3) culture is a learned behavior, it is universal, and it is not static but in a constant state of change and adaptation. However, in the late nineteenth and early twentieth centuries, the concept of culture was primarily based on describing the physical characteristics, material objects, and kinship structures of non-European and nonEuro-American peoples. Culture was empirical and tangible; it was defined by geographical areas and it could be measured, named, and classified. By the mid-late twentieth century, cultural anthropology shifted from a descriptive science to an interpretive discipline analyzing the meanings humans constructed to explain the values and ethics that guided their lives. According to one of the preeminent anthropologists of the second-half of the twentieth century, the late Clifford Geertz, the primary role of the cultural anthropologist is to use 'thick description' to describe and interpret these various 'webs of significance' (1973). For Geertz, culture is a symbolic system that gives both an account of the world (describes) and outlines a set of rules for acting in it (prescribes). Despite Geertz's widespread influence, a lack of consensus continues in anthropology about what culture is, what it does, and how it changes. Today, the culture concept in anthropology ranges from an emphasis on the behavioral (culture is a learned behavior), to the functional (culture is human adaptation to the physical and biological environment), to the ideational (culture is shared ideas and symbolic systems of explanation).

Beyond anthropology, the observation that culture, however defined, is a significant determinant of population health is a recent development in public health research and practice. However, a similar lack of consensus concerning the definition of culture and its relationship to health plagues the public health literature and threatens the success of interventions to improve both individual and population-level health. For example, public health interventions to reduce transmission of HIV/AIDS have variously focused on culture as a barrier to change (among Latino men, the culture of machismo can prevent self-identification as a person who engages in samesex behaviors) as well as a facilitator of change (in Uganda, the traditional practice of widow-inheritance whereby the brother of the deceased husband marries the widow, is now marked by a symbolic ceremony rather than an actual marriage, thus reducing the risk of transmission of the HIV virus). The study of culture as a determinant of population-level health is an outgrowth of Wilkinson and Marmot's (2003) research on the socioeconomic determinants of health and other contributions to the development of social epidemiology. However, it is essential that epidemiologists avoid resurrecting the nineteenth-century definition of culture which focused on culture as a reified object, behavior, or belief that existed outside a political, economic, and historical context. Culture is never a unified whole, and its impact on health is unevenly distributed both between societies and within them. Analyzing the nature of that relationship - causal or associational - is yet another challenge in the application of the culture concept to public health practice.

\section{The Anthropological Method}

The hallmarks of anthropological research are fieldwork and participant observation. In contrast to research conducted in the controlled settings of a clinic or laboratory, anthropological research is conducted in the place where the study population lives and works everyday; this is the 'field' and anthropological data collection is 'fieldwork.' To understand a cultural system as fully as possible, classic cultural anthropological fieldwork consists of the researcher spending an extended period of time in a village, town, or city where they learn at least the basics of the local language and develop trust and rapport with their neighbors and others in the community. Anthropologists observe daily life and keep detailed notes on what they learn, hoping to discover the hidden patterns of meaning and social significance which appear to the community to be so natural as to be literally invisible. The process of moving beyond the role of outside observer into the deeper understanding of the cultural 'insider' is achieved primarily through participant observation, the signature anthropological method. By literally participating in everyday activities, rituals, and celebrations, an anthropologist hopes to gain a new perspective on 
the culture. To master these skills, it is common for an anthropologist to return to the same region repeatedly, even over their entire academic career. However, participant observation is only one of many different types of data collection anthropologists will use; other methods include archival research, indepth interviews, surveys, demographic data, basic health measurements (height, weight, nutritional analysis, diagnostic testing for infectious disease), etc. The use of these similar research methods creates a bridge between anthropology and public health, promoting the citation of each other's data and facilitating constructive collaboration on difficult and complex health issues, such as enforcing quarantine procedures during an Ebola outbreak or vaccinating children against polio when other health concerns, such as malaria or malnutrition, are considered a higher priority by the local population.

\section{Anthropological Perspectives in Public Health Ethics}

The anthropological perspective in bioethics and public health ethics is evident in three areas: (1) the influence of anthropology's culture concept on the practice or application of ethics in public health, (2) the adoption of anthropological methods and perspectives in research on public health and bioethics research, and (3) the study, by anthropologists, of the fields of public health and bioethics as distinct cultures themselves. Anthropology's involvement in bioethics flourished in the 1990s as complex health-related concerns, such as decision making regarding biotechnology and end-of-life care, were no longer satisfactorily addressed by professional or academic bioethicists. Growing out of medical sociology and its focus on the doctor-patient relationship, anthropologists expanded research on health communication to explore, for example, the impact of gender and medical authority on patient communication and outcomes. Anthropologists also studied cultural interpretations of human biological processes. For example, in the Buddhist tradition, brain death is not accepted as the definitive marker of the end of human life; this and other culturally determined beliefs significantly restrict options for organ transplantation (Scheper-Hughes, 2008). In another example of the influence of culture on the social meaning of disease, Japanese women do not report the same physical symptoms related to menopause as American women; and when they do experience similar physical symptoms, Japanese women underreport them in comparison to American women (Lock, 1993). Therefore, therapies for aging women in Japan are significantly different than those for American women. Through the ethnographic method, anthropology foregrounds the experiences of individuals and the moral frameworks that govern their ethical decision making, thus challenging bioethics' focus on hegemonic ethical norms or biomedical authority (Kleinman, 1999, 2006). Anthropology also moves the study of bioethics into non-Western contexts, expanding its narrow geographical scope and promoting the importance of cross-cultural analysis; for example, introducing public health interventions to eliminate female feticide in South Asia. The central lessons of anthropology for public health are as follows: (1) the human experience of health, illness, and disease is shaped not only by biological facts, but also by social and cultural issues and (2) health-seeking behavior and decision making are significantly influenced by historical and economic contexts. Anthropological research demonstrates that local moral experiences and norms of reproduction, immunization, body modification, genetic testing, and research participation as well as definitions of health, personhood, or death, are key variables shaping public health outcomes (Feierman et al., 2010).

\section{Anthropology and the Ethics of Public Health Practice}

One of the most influential American medical anthropologists is Arthur Kleinman, a practicing psychiatrist and professor of anthropology. In an effort to improve communication between provider and patient in biomedical and public health settings, Kleinman pioneered a simple, but highly effective, series of eight questions to explore the experience of illness from the patient's perspective (Kleinman, 1980). His 'Explanatory Model' method probes individual cultural interpretations of sickness through the use of standard anthropological interview techniques that establish rapport between the patient and the interviewer, encourage open-ended responses, and validate the individual illness experience even when biomedical or epidemiological models do not recognize the patient's symptoms or explanations.

1. What do you call the problem?

2. What do you think has caused the problem?

3. Why do you think it started when it did?

4. What do you think the sickness does? How does it work?

5. How severe is the sickness? Will it have a short or long course?

6. What kind of treatment do you think the patient should receive? What are the most important results you hope they receive from this treatment?

7. What are the chief problems the sickness has caused?

8. What do you fear most about the sickness?

The current focus on cultural competency in health care is rooted in the widespread adoption of Kleinman's model. Anne Fadiman's (1997) award-winning book, The spirit catches you and you fall down: a Hmong child, her American doctors, and the collision of two cultures, is a study of a catastrophic breakdown in communication between an immigrant Hmong family and the public health system in Merced, California. It is widely cited as an example of a tragic health outcome that probably could have been averted if the local health officials had embraced Kleinman's approach. The Hmong example highlights several ethical dilemmas facing most health practitioners. How does an individual health professional engaged in public service balance the need for intensive individual attention to achieve the highest health outcomes against the reality of limited resources? To what extent is a health professional obligated to acknowledge and understand the culture-bound health models of their patients? Can a practitioner ever transgress public health policy in order to better serve one individual? Anthropological knowledge of local cultural models of illness can play a significant role in answering these public health ethical questions.

The challenges of delivering care and enforcing quarantine in a hemorrhagic fever outbreak underscore similar ethical dilemmas for public health specialists. Two recent examples 
from Africa, Ebola virus in northern Uganda in 2000 and Marburg virus in the border region of Angola and Congo in 2005, clearly demonstrate both the positive effect of applying local cultural models of disease transmission to disease response efforts and the negative outcomes that can result from a lack of collaboration between epidemiologists and anthropologists. Applying Kleinman's explanatory model, epidemiologists and social scientists from the US Centers for Disease Control and Prevention dramatically reduced the number of new Ebola cases in Uganda in 2000 by immediately collaborating with traditional healers to modify local high-risk burial practices. The epidemic was quickly and effectively contained (Hewlett and Amola, 2003). In contrast, Angola, which suffered the largest outbreak of Marburg virus on record, delayed their response several months after discovering the first case. In lieu of working with the local community, the Angolan government dispatched soldiers to this already chronically underserved area, resulting in local refusal to accept quarantine restrictions and inciting serious violence against public health workers. Health workers, both local and international, pressed by the urgency of the situation, deployed stringent quarantine protocols even though they recognized that these activities clearly heightened local fear, stigma, and violence. All public health interventions require a balance between benefits, risks, harms, and costs; however, including anthropological analysis in this intervention process could have drawn attention to the critical economic and political circumstances which shaped Angolan health behaviors related to the transmission of the Marburg virus. The ethical dilemma for these public health workers was to assess the paradox of continuing to deliver services designed to contain the epidemic but which actually contributed to the transmission of the virus versus suspending services until community cooperation could be organized. Public health actions, especially those implemented in high-risk crisis situations, have a higher rate of success if local cultural models of disease transmission are incorporated into the intervention planning from the onset of the epidemic. Tragically, this lesson was not applied in the devastating West African Ebola crisis where more than 11000 people died in Guinea, Liberia, and Sierre Leone between 2014 and 2016. As with the 2005 outbreak in Angola, many West Africans distrusted their public health system and refused to cooperate with medical workers who abruptly arrived in villages to remove suspected Ebola cases. The lack of transparency in implementing public health interventions, such as the government-sanctioned, but ill-advised and ultimately ineffective quarantine in the West Point area of Monrovia, Liberia in 2014, severely undermined participatory community decision-making efforts which are essential for changing Ebola-related risk behaviors, especially burial practices (Ebola Response Anthropology Platform).

Another example of a tragic public health outcome directly related to the mismanagement of communication between public health workers and local communities is the 2003-04 polio immunization crisis in northern Nigeria. Between 1988 and 2002, the WHO Global Polio Eradication Initiative, the world's single-largest, internationally coordinated public health project, reduced the number of cases of wild polio virus worldwide by $99 \%$. However, in August 2003, three states in northern Nigeria suspended polio immunization campaigns, following concerns by some public figures regarding the safety of the polio vaccine. Local political and religious leaders counseled parents to refuse the polio vaccine and accused Western countries of deliberately contaminating the vaccine in a plot to sterilize African children, particularly Muslim children. Subsequently, a new outbreak occurred, originating in the northern state of Kano, reinfecting previously polio-free areas within Nigeria (including Lagos) and eight previously poliofree countries across west and central Africa. As a result, for the first time since efforts to eradicate polio began, more countries suffered polio cases in 2003 due to importations than were themselves endemic for the disease. Within 12 months, polio eradication campaigns resumed across northern Nigeria in July 2004. However, Nigeria continues to report wild polio virus. In 2006, 1124 cases were identified in Nigeria, accounting for well over two-thirds of the total number of cases worldwide

Local anxieties about the 2003 polio campaign in Nigeria reflect a difficult history of externally supervised public health projects. It is widely believed that the deaths of five children enrolled in a 1996 research study in northern Nigeria were caused by the unethical use of Trovafloxacin (Trovan), a vaccine produced by Pfizer to combat meningitis. Even before this tragedy, aggressive antifertility campaigns sponsored by the southern-dominated Nigerian government in the 1980s generated mistrust of the public health system in the northern areas of the country. The significance of these facts was grossly underestimated by the implementers of the Kick Polio out of Africa campaign. However, anthropological analysis offers a clearer assessment of why parents refused an effective life-saving public health intervention while public health ethics outlines a more responsive, and ultimately effective, approach to mass vaccination conducted in an atmosphere of fear and mistrust. Several anthropologists cautioned that local suspicion of the polio eradication campaign was rooted in the stark contrast between the well-organized and free delivery of the polio vaccine and the chronically underfunded and dysfunctional primary health care system (Renne, 2006). Furthermore, from the perspective of the local community, more pressing health issues, such as malnutrition or malaria, were consistently ignored by public health officials. Even the 2003 Nigerian government report that confirmed the safety of the polio vaccine was rejected by the northern states because the local Muslim community did not participate in the production of the government report. The impasse was finally broken after the government and external health agencies consulted with the local communities and fresh testing of the polio vaccine was commissioned in Muslim-operated biomedical facilities in Muslim countries. One of the primary principles of ethical public health decision making is a respect for autonomy and human dignity; this is the opposite of the paternalism demonstrated by both the Nigerian government and international sponsors early in the immunization campaign. However, in 2008, Muhammad Ali Pate was appointed to transform the polio eradication campaign in Nigeria. Within 2 years, new cases of polio dropped to 21, the lowest ever recorded in Nigeria. Although not a trained anthropologist, Pate relied on some classic techniques of anthropological fieldwork to gain the trust of northern Nigerians who refused to allow their children to be immunized against polio. As Minister 
of Health, he arrived in a village on foot and not by chauffeured car, he wore the same simple jalabiya worn by other men in the village, and he spent time developing rapport and trust with the community by listening to their grievances (Roberts, 2013). Pate incorporated these techniques into a new standard protocol that field workers followed whenever they approached the homes of polio refusers. In September 2015, the WHO declared wild polio virus no longer endemic in Nigeria, leaving only Pakistan and Afghanistan with wild circulating polio virus. Understanding local cultural norms is a cornerstone for effective collaboration between public health workers and community leaders and members. Anthropology can help public health workers anticipate when health-intervention protocols may be at odds with local sentiments, thus avoiding these tragic break-downs of communication between the community and the public health sector.

In addition to these examples of anthropological contributions to ethical matters in public health interventions and clinical practice, anthropologists are part of a renewed focus on the social determinants of health and the impact of the organization of health systems on health outcomes, such as life expectancy at birth, infant mortality, and overall morbidity. Thomas McKeown demonstrated the importance of economic growth, rising living standards, and improved nutrition, rather than the development of scientific medicine or the public health movement, as the primary driver of mortality decline in Britain (McKeown and Brown, 1955). Michael Marmot's Whitehall study shows that even in the absence of poverty, social hierarchies and economic disparities lead to inequalities in health outcomes (Marmot et al., 1991). Davidson Gwatkin et al. (2005) at the World Bank discovered that most interventions aimed at alleviating poverty and improving health in poor countries usually benefit the middle tier more than the most disadvantaged. Richard Wilkinson (1996) demonstrated that high wealth does not always guarantee the best health; it is the countries with the smallest income gaps that have the best overall health. In light of these findings, public health practitioners are turning to the ethical principles of distributive justice (Rawls, 1985; Daniels et al., 1999) to argue that achieving equity in health is our brightest hope for significantly improving global health. Equity is a value-based ethical concept that means social justice or fairness. Unlike the descriptive fact of equality, equity is an ethical assessment often calling for action or change. Equity in health is defined as 'differences in health that are not only unnecessary and avoidable, but in addition, unfair and unjust' (Whitehead, 1992); equity in health calls for the elimination of the social and economic barriers that lead to these disparities. However, some disparities are unavoidable (genetics) yet others are clearly avoidable (access to care). Inequities in access to health systems must be addressed by public health practitioners because they systematically exacerbate the health of people already socially and economically marginalized.

In 1990, Mongolia began a transition from a soviet-style socialist public health system to one based on such liberal economic reforms as the privatization of health care in a free market system. Mongolia is an exceptional case study of the deleterious effects of the rapid expansion of social and economic inequalities on health outcomes. Anthropological inquiry can contribute to explaining how and why those hierarchies amplify poor health by analyzing them in a broader historical and sociocultural framework. For over 70 years, the socialist government in Mongolia delivered adequate levels of access to biomedicine. However, within 2 years of the sudden introduction of neoliberal reforms, GDP dropped 20\% and the delivery of health services deteriorated as the public health budget shrank. But most significantly, between 1995 and 2000, the social inequality index (GINI index) rose $20 \%$. Craig Janes, a medical anthropologist, argues that the case of Mongolia clearly demonstrates how strategies for health reform, developed by a few influential macroeconomists in the centers of global health governance, meet and articulate with local-level health policies and practices. These social and institutional 'borderlands' (Janes et al., 2006: p. 7) literally embody the collision of neoliberal global health discourses with local realities, and the result is a devastating increase in health inequities. Janes' research confirms Gwatkin's observation that the vulnerable poor suffer more than any other group as access to health services beyond the primary care system are privatized. Careful anthropological interviewing of female heads of households elicited personal narratives of illness episodes that cogently demonstrated the flawed assumption that, in the case of rural Mongolia, privatized health care is an efficient distribution of health care resources. An equity analysis focuses on the unnecessary and unfair imbalance in access to services between the rich and poor, confirming that "essential care" for the poor is little more than poor medicine.' And finally, the architects of global health governance must be held responsible for the local consequences of their global 'good ideas' (Janes et al., 2006: pp. 26-27).

\section{Anthropology and the Ethics of Public Health research}

In 2001, the US President's National Bioethics Advisory Commission (NBAC) published a major report which recommended that US-based Institutional Review Boards (IRBs) become more familiar with the local realities of developing countries, especially those conditions that affected the ability of researchers to conduct ethical health research. This recommendation was based, in part, on anthropological research presented to NBAC on the cultural implications of health research in resource-poor settings (Marshall, 2001). NBAC further recommended that the United State encourage and facilitate ethically sound collaborative health research. This recommendation is a response to one of the most hotly contested debates in the conduct of US-sponsored health research in developing countries: the ethical standing of the international implementation of the US AIDS Clinical Trial Group (ACTG) study protocol 076 to reduce mother-to-child transmission (MTCT) of the HIV virus. By the 1990s, the life expectancy in several African countries had dropped by as much as 20 years as a result of the HIV epidemic. Treatment was widely available in resource-rich countries, but only zidovudine (AZT), the treatment to reduce MTCT of the HIV virus, was potentially within the budgets of African countries. The NIH and CDC funded several research trials to test the hypothesis that a lower, and therefore less expensive, dose of AZT was equally effective in reducing MTCT in resource-poor settings. By 1998, international controversy swelled over the use of a placebo research design to test the hypothesis. In 
simplistic terms, one position argued that the use of a placebo design was unethical because an effective dose of AZT was already established, while another position argued that the current standard dose was only affordable in the West and therefore the placebo design was ethical during an epidemic in order to test the hypothesis as quickly as possible. This case opened a new era in the discussion of ethics of international health research. Anthropologists have contributed to this debate and their cultural research is cited in new guidelines for the ethical conduct for international public health research in resource-poor countries (Marshall, 2001).

As outlined in the US Belmont Report, one of the central principles of ethical health research, autonomy (respect for persons), holds that each individual research participant should be treated as an autonomous agent. For public health researchers, the concept of autonomy demands they demonstrate that research participants enter into the research process voluntarily. In the context of health research in Africa, for example, the determination that research participants freely and voluntarily give consent to participate is sometimes difficult to assess because in some cases, individuals, such as married women, do not give consent in the same manner as individuals in the United States, but rather defer to husbands or village leaders to indicate consent for them. Overemphasis on this specific case has narrowed the debate over autonomy in Africa to the notion that Africans have no sense of individual personhood, but rather organize themselves communally and do not recognize individual rights over the rights of the community (Stewart and Sewankambo, 2010). The anthropological literature on African philosophy offers two important points about African concepts of autonomy and communality. First, African personhood is not a static identity or a function of a legal age of consent; instead, personhood for many Africans is a dynamic process that changes over a lifetime and therefore challenges the Western concept that individual autonomy is reached at age of 18 years and is permanent until infirmity or death. Second, many Africanist anthropologists argue that this contrast between community and individual is overstated; both concepts exist in African societies but the important question is which concept takes precedence in which situation and for what reasons. Therefore, it is critical to test the contours of the concept of autonomy in specific situations; for example, in the context of the lived experiences of Africans participating in health research. The toolbox of the anthropologist is best suited for this task.

The second important concept listed in the Belmont Report is beneficence, or an obligation to do no harm to a research participant and to maximize benefits for the participant. There are two types of benefits: first, the material benefits to the individual or the community related directly to the research itself such as compensation and medical services and second, a larger responsibility of the research project to improve society through capacity building, such as training, or other obligations beyond the tenure of the research project. In the context of HIV/AIDS research in Africa, controversy over this concept is related to the issue of standard of care; that is, should international researchers offer local participants the same standard of care they would receive if they were a research participant in the United States, or is the international researcher only obligated to offer the local standard of medical service, which may in fact be no medical service at all? The current debate about beneficence is limited to technical, legal, and logistical concerns. Anthropologists broaden the discussion to consider what the local research community itself holds to be a reasonable balance between a community's cooperation with a research project and the investigators' responsibility to the participants beyond the standard issues of safety and informed consent. For example, if an experimental intervention cannot be sustained beyond the end of the research study, researchers are now considering broader benefits, such as a new bore hole for clean water, to recognize the contribution of the local community to the research study. Is it now not unreasonable to suggest that health researchers negotiate a sort of bilateral agreement between the research project and the community for benefits beyond individual compensation of the research participant. Anthropological research, focusing on the local perspective of research and the individual experiences of the research participant, has contributed to broadening the concepts of benefits, community, and collaboration in health research. By studying the contrasts in the concepts of beneficence between researcher and participant, for example, we can more clearly understand how local communities themselves define the ethical and proper relationship between research, health interventions, education, and development (Stewart and Sewankambo, 2010).

Finally, public health researchers increasingly acknowledge the importance of understanding cultural models of the body before collecting human biospecimens, such as tissue, hair follicles, breast milk, semen, and of course, blood. Standard ethical issues related to the conduct of research with human biologic materials are informed consent, ownership of the specimens, and the commercial value of research results. However, new issues concerning ethically appropriate methods of collection, storage, and use focus on the social meaning and cultural values of the human biologic material itself in the community, outside its functional role in the research study. A central topic is the power of the biologic specimen to redefine the donor's personal identity or reshape their relationship to their family or community. For example, the placenta holds great cultural value for many societies, yet it is treated as a piece of disposable, potentially infectious human tissue in the Western hospital setting. Ownership of the placenta was at the center of some of the conflicts discussed above between immigrant Hmong communities and hospital staff in Merced, California. Burying the placenta under or near the family home is an important cultural ritual for many groups. In fact, the unwillingness of the Merced hospital to allow Hmong mothers to return home after a hospital delivery with their placentas fueled a preference to deliver outside the hospital (Fadiman, 1997), thus increasing risk to both the mother and the baby.

Genetic research, specifically DNA analysis for such epidemiologic purposes as identifying risk of birth defects, understanding disease etiology, pharmacogenetic testing for variation in drug response, or measuring exposure to environmental hazards, also presents new cultural and social challenges for health researchers. Group membership, for example in a family, kin group, or ethnic group, typically is defined and maintained by social interactions. Genetic testing may conflict with the lived experience of an individual in 
a family (paternity), an ethnic group (a specific Native American tribe), or a religious community (Ashkenazi Jews). Which identity should an individual claim: their lived identity or that of their genome and which category of genetic information should take precedence over another in determining identity when access to valuable resources might be at stake? One of the largest international genetic research studies, the International HapMap project, is a population-based study to discover genes associated with human health and disease and to identify genes that mediate individual responses to medications and environmental insults. A significant ethical challenge with all genetic research is to anticipate and mitigate potential stigma which could devastate small, vulnerable social groups, such as Native Americans in the United States. Is it ethically responsible to conduct research on a biologically defined population group if some group members oppose the research on the principle that their genome will be studied without their consent? Identifying a socially defined group based on genomic evidence implicates the entire social group, not just those with the genetic marker of interest. A central goal of anthropology is to study race and ethnicity as primarily cultural and historical constructs. While geneticists assign racial and ethnic identity based on biology, in contrast, anthropologists privilege the lived experience of an individual member of a population group and analyze many other nonbiological variables before attributing membership to one group or another. Insights from the anthropological study of group identity, definitions of community, and social norms regulating group membership improve the ethical dimensions of health research with human biospecimens and contribute to a deeper understanding of the social implications of genetic epidemiology.

\section{Anthropology and Ethics at the Intersection of Public Health Practice and Research: Zika Virus Outbreak in Brazil}

Zika flavivirus was first discovered in 1947 in a sentinel rhesus macaque monkey in Uganda and the first human cases were detected in Uganda and Tanzania in 1952. Subsequent outbreaks outside Africa and Southeast Asia were rare until 2007 when a major epidemic occurred in Micronesia. Zika virus was first identified in the Americas in Brazil in March 2015 during an outbreak which is linked to the 2014 FIFA World Cup event. By June 2016, Zika virus had spread to 60 countries, 46 of which had no previous evidence of circulation, while 9 reported evidence of nonmosquito, person-to-person transmission, widely assumed to be transmitted via sexual contact (WHO, 2016).

Zika is primarily transmitted to humans by the Aedes mosquito, particularly Aedes aesypti, a type of mosquito that prefers living near, and feeding on, humans. Transmission of the Zika virus is similar to dengue, yellow fever, and chikungunya viruses. Previous to the widespread transmission of Zika virus in Brazil in late 2014, Zika virus infection was generally thought to cause only mild to moderate flulike symptoms including fever, rash, conjunctivitis, and arthralgia (joint pain) which appeared in only about $20 \%$ of the infected population (Peterson et al., 2016). However, by September 2015, there was a sudden and significant increase in the prevalence of microcephaly in infants born to Brazilian women living in areas with confirmed Zika virus (Kleber de Oliveira et al., 2016). In November 2015, Brazil declared the cluster of microcephaly cases a public health emergency, and in February 2016, the WHO declared Zika a Public Health Emergency of International Concern (PHEIC). Two months later, scientists at the CDC concluded that a prenatal Zika virus infection, particularly in the first trimester of pregnancy, can cause fetal or infant microcephaly and other serious congenital brain malformations (Rasmussen et al., 2016). This is the first time a mosquitoborne disease was determined to cause severe congenital abnormalities. Nearly one-third of women in Brazil who reported Zika virus infection during pregnancy delivered children with a range of fetal abnormalities. Zika is also linked to Guillain-Barré syndrome, and there is strong evidence for sexual transmission, and possibly via blood transfusion which is a serious concern since most people infected with the Zika virus are asymptomatic.

Zika virus raises a range of ethical questions in a variety of spheres: local health care delivery, global NGO governance and surveillance, local government responsibility for vector control, public health prevention, special needs resources for affected children, and women's sexual, reproductive, and human rights. Anthropologists can be central to identifying and clarifying these ethical dilemmas at the intersection of public health practice and research. In terms of public health practice, the Zika outbreak in Brazil lays bare conflicting norms, beliefs, values, and practices across many domains of society (religious, legal, political, economic) that affect the rights of women in Brazil to control their reproductive health and protect the health of future children. Which frameworks should take precedence during this outbreak: religious values that discourage the use of contraception and prohibit termination of a pregnancy? National laws that limit or criminalize access to abortion? global human rights declarations (to which Brazil is a signatory) that defend a woman's right to reproductive health services, including abortion? Social justice supporters who point to the unfair paradox that the burden of Zika virus in Brazil is borne almost entirely by the youngest, poorest, and least educated women (and their children) who live in neighborhoods where reproductive health services are unavailable and the public sector has failed to control the mosquito? Debora Diniz, a Brazilian anthropologist, bioethicist, and professor of law, clearly identifies this 'intersectional discrimination.' She strongly advocates for anthropological knowledge of the lived experiences of individual 'Zika mothers' to expose the complex web of social, religious, political, and economic factors that expose these pregnant Brazilian women to greater risk of Zika infection and to explore the seemingly contradictory behavior that reflects the deep existential torment of women who refuse ultrasound technology to identify abnormal fetuses due to a of lack of options for preventing, delaying, and terminating pregnancies in Brazil (Diniz, 2016a,b).

In terms of public health research, Zika virus causes a wide variety of health effects, from mild flulike symptoms to fetal abnormalities to Guillain-Barré syndrome, of which the most severe effects were previously unknown. Conducting medical and public health research during an outbreak is essential to 
understand the virus and to develop prevention and intervention programs for the future (Nuffield Council, 2016). A key feature of public health research is surveillance data. After the disastrous delay by both the WHO and the global community to act swiftly to contain Ebola during the 2014-15 west African outbreak, early into the Brazilian Zika virus crisis the WHO highlighted the importance of increasing public availability of all Zika-related epidemiologic data. In contrast, the biomedical protocols for including pregnant women in clinical trial research are underdeveloped and inadequate (Harris et al., 2016). This is due to longstanding legal frameworks and ethical arguments that exclude pregnant women from participating in medical research due to a fear of the possible detrimental effects of experimental vaccines and drug treatments on pregnant women's bodies and their fetuses. Furthermore, it is unclear whether to invoke one of the key principles guiding the ethical conduct of human subjects research - beneficence (do no harm) - for the benefit of the mother or the fetus. As a result of these ethical challenges related to public health and biomedical research, during a public health crisis such as the Zika virus outbreak in Brazil, pregnant women suffer a double burden: heightened health risk compounded by a lack of research into safe and effective treatment and prevention options.

\section{Future Directions: Toward a Global Public Health Ethics Informed by Anthropology}

Clearly, the challenges of conducting ethically sound, morally satisfying, collaborative health research continue to outpace the development of an internationally recognized global public health ethic. At this moment, it appears that global public health ethics are reactive, not proactive; therefore, the strategy needs to shift to a predictive mode which can anticipate emerging trends which might benefit from a global public health ethics analysis (Stewart et al., 2010). The field of global public health ethics should build a pluralistic ethical framework based on empirical, social scientific data grounded in the locally experienced effects of global processes, sometimes referred to as the 'glocal.' For the fields of anthropology, global public health, and bioethics this means examining social values that might appear conceptually similar across a diversity of cultural traditions but in practice be very different. As discussed above, the concept of autonomy is clearly present in doctor-patient decision making in both Asian and American settings, but in Asia, autonomy in the context of disclosure of end-of-life information is often located in the patient's family while in the West, the focus is on confidential disclosure directly to the individual patient. Similarly, the concept of risk and other Western ideals related to ethical standards for participation in medical research, as codified in the US-authored Belmont Report, are ill suited for direct translation into the local language of the research participants (Stewart and Sewankambo, 2010; Lawrence and Stewart, 2016). Resolving this conceptual gap demands not more regulation, but deeper cultural analysis of both sides of the intersection between participant knowledge and research instruments in global public health research. Global governance of medical research and public health-care practice is debated, defined, and established beyond the borders of nation states, yet its ultimate relevance and success is dependent on the acceptance of these regulations and practices at the local level where they become lived experiences. Therefore, the challenge of global public health ethics in the twenty-first century is not to preemptively regulate it through abstract universal declarations, for example, but first to document the global diversity of bioethics beliefs and practices and then to confront the challenge of building a new field of inquiry, global public health ethics, in full consideration of this diversity.

See also: Codes of Ethics in Public Health; Ethics and Health

Promotion; Ethics of Immunization; Ethics of Infectious

Disease Control; Ethics of Organ Transplants; Ethics of

Screening; Foundations in Public Health Ethics.

\section{References}

Daniels, N., Kennedy, B., Kawachi, I., 1999. Why justice is good for our health: the social determinants of health inequalities. Daedalus 128, 215-251.

Diniz, D., February 8, 2016a. The Zika Virus and a Brazilian Women's Right to Choose. New York Times, p. A25

Diniz, D., 2016b. Zika virus and women. Cad. Saúde Pública 2, 1-4.

Ebola Response Anthropology Platform - http://www.ebola-anthropology.net/aboutthe-network/.

Fadiman, A., 1997. The Spirit Catches You and You Fall Down: A Hmong Child, Her American Doctors, and the Collision of Two Cultures. Farrar, Straus, and Giroux, New York, NY.

Feierman, S., Kleinman, A., Stewart, K., Farmer, P., Das, V., 2010. Anthropology, knowledge-flows, and global health. Glob. Public Health 5, 122-128.

Geertz, C., 1973. The Interpretation of Cultures: Selected Essays. Basic Books, New York.

Gwatkin, D., Wafstaff, A., Yazbeck, A.S., 2005. Reaching the Poor with Health, Nutrition, and Population Services. International Bank for Reconstruction and Development (World Bank), Washington DC.

Harris, L.H., Silverman, N.S., Marshall, M.F., 2016. The paradigm of the paradox: women, pregnant women, and the unequal burdens of the Zika virus pandemic Am. J. Bioeth. 16, 1-4.

Hewlett, B.S., Amola, R.P., 2003. Cultural contexts of Ebola in northern Uganda Emerg. Infect. Dis. 9, 1242-1248.

Janes, C.R., Chuluundorj, O., Hilliard, C.E., Rak, K., Janchiv, K., 2006. Poor medicine for poor people? Assessing the impact of neoliberal reform on health care equity in a post-socialist context. Glob. Public Health 1, 5-30.

Kleber de Oliveira, W., Cortez-Escalante, J., De Oliveira, W.T., et al., 2016. Increase in reported prevalence of microcephaly in infants born to women living in areas with confirmed Zika virus transmission during the first trimester of pregnancy - Brazil. Morb. Mortal. Wkly. Rep. 65, 242-247.

Kleinman, A., 1980. Patients and Healers in the Context of Culture: An Exploration of the Borderland between Anthropology, Medicine, and Psychiatry. University of California Press, Berkeley.

Kleinman, A., 1999. Moral experience and ethical reflection: can ethnography reconcile them? a quandary for 'the new bioethics'. Daedalus 128, 69-97.

Kleinman, A., 2006. What Really Matters: Living a Moral Life amidst Uncertainty and Danger. Oxford University Press, Cambridge.

Lawrence, C., Stewart, K., 2016. Community advisory boards in Uganda: best practices. J. Empir. Res. Hum. Res. Ethics V.

Lock, M., 1993. Encounters with Aging: Mythologies of Menopause in Japan and North America. University of California Press, Berkeley.

Marmot, M.G., Smith, G.D., Stansfeld, S., Patel, C., North, F., Head, J., White, I., Brunner, E., Feeney, A., 1991. Health inequalities among British civil servants: the Whitehall II study. Lancet 337, 1387-1393.

Marshall, P.A., 2001. The relevance of culture for informed consent in U.S. funded international health research. In: National Bioethics Advisory Commission (Ed.), Ethical and Policy Issues in International Research: Clinical Trials in Developing Countries, Commissioned Papers and Staff Analysis, vol. II. National Bioethics Advisory Commission, Bethesda, MD, pp. C1-C38. 
McKeown, T., Brown, R.G., 1955. Medical evidence related to English population changes in the eighteenth century. Popul. Stud. 9, 119-141.

Nuffield Council, 2016. Zika: Ethical Considerations. Briefing Note. http:// nuffieldbioethics.org/news/2016/zika-ethical-considerations/.

Peterson, L.R., Jamieson, D.J., Powers, A.M., Honein, M.A., 2016. Zika virus. N. Engl. J. Med. 374, 1552-1563.

Rasmussen, S.A., Jamieson, D.J., Honein, M.A., Petersen, L.R., 2016. Zika virus and birth defects: reviewing the evidence for causality. N. Engl. J. Med. 374 1981-1987.

Rawls, J., 1985. Justice as fairness: political not metaphysical. Philos. Public Aff. 14 223-251.

Renne, E., 2006. Perspectives on polio and immunization in northern Nigeria. Soc. Sci. Med. 63, 1857-1869.

Roberts, L., 2013. The art of eradicating polio. Science 342, 28-35.

Scheper-Hughes, N., 2008. A World Cut in Two: The Global Traffic in Organs. University of California Press, Berkeley.

Stewart, K., Keusch, G., Kleinman, A., 2011. Bridging the local and the global: values and moral experiences in global health. In: Benatar, S., Brock, G. (Eds.), Global Health and Global Health Ethics. Cambridge University Press, Cambridge, UK, pp. 304-310.

Stewart, K., Kleinman, A., Keusch, G., 2010. Introduction: values and moral experience in global health: bridging the local and the global. Glob. Public Health $5,115-121$.

Stewart, K., Sewankambo, N., 2010. Okukkera Ng'omuzungu (lost in translation): understanding the social value of global health research for HIV/AIDS research participants in Uganda. Glob. Public Health 5, 164-180.

Whitehead, M., 1992. The concepts and principles of equity and health. Int. J. Health Serv. 22, 429-445

Wilkinson, R., 1996. Unhealthy Societies: The Afflictions of Inequality. Routledge, London and New York.

Wilkinson, R., Marmot, M., 2003. Social Determinants of Health: The Solid Facts, second ed. WHO, Copenhagen.

WHO, 2016. Zika Situation Report. http://www.who.int/emergencies/zika-virus/ situation-report/2-june-2016/en/.

\section{Further Reading}

Abu-Lughod, L., 1991. Writing against culture. In: Fox, R. (Ed.), Recapturing Anthropology: Working in the Present. School of American Research Press, Santa Fe, NM, pp. 137-162

Anand, S., Peter, F., Sen, A. (Eds.), 2004. Public Health, Ethics, and Equity. Oxford University Press, Oxford.

Beauchamp, D.E., Steinbock, B. (Eds.), 1999. New Ethics for the Public's Health Oxford University Press, New York

Bernard, R.H., 2011. Research Methods in Anthropology: Qualitative and Quantitative Approaches, fifth ed. AltaMira Press, Walnut Creek, CA.

Clifford, J., Marcus, G.E., 1986. Writing Culture: The Poetics and Politics of Ethnography. University of California Press, Berkeley.

Farmer, P., 2004. Pathologies of Power: Health, Human Rights, and the New War on the Poor. University of California Press, Berkeley.

Fox, R., 1990. The evolution of American bioethics: a sociological perspective. In: Weisz, G. (Ed.), Social Science Perspectives on Medical Ethics. Kluwer Academic Publishers, Dordrecht.

Janes, C.R., 2004. Going global in century XXI: medical anthropology and the new primary health care. Hum. Organ. J. Soc. Appl. Anthropol. 63, 457-471.

Kleinman, A., 1995. Writing at the Margin: Discourse between Anthropology and Medicine. University of California Press, Berkeley.

Krieger, N. (Ed.), 2005. Embodying Inequality: Epidemiologic Perspectives. Baywood, Amityville, NY.

Marcus, G.E., Fischer, M.J., 1986. Anthropology as Cultural Critique: An Experimental Moment in the Human Sciences. University of Chicago Press, Chicago.

Marshall, P.A., Koenig, B.A., 1996. Bioethics in anthropology: perspectives on culture medicine, and morality. In: Sargent, C.F., Johnson, T.M. (Eds.), Handbook of Medical Anthropology: Contemporary Theory and Method, revised ed. Greenwood Press, Westport, CT, pp. 349-373.

Trostle, J.A., 2005. Epidemiology and Culture. Cambridge University Press, Cambridge. 